\title{
Critical appraisal of the role of everolimus in advanced neuroendocrine tumors of pancreatic origin
}

This article was published in the following Dove Press journal:

Gastrointestinal Cancer:Targets and Therapy

26 September 2012

Number of times this article has been viewed

\author{
Núria Mulet-Margalef \\ Jaume Capdevila \\ Medical Oncology Department, \\ Vall d'Hebron University Hospital, \\ Barcelona, Spain
}

Correspondence: Jaume Capdevila Medical Oncology Department, Gastrointestinal and Endocrine Tumor Unit, Vall d'Hebron University Hospital, Pg Vall d'Hebron, II9-129,

08035 Barcelona, Spain

Tel +349 34894350

Fax +3493274678I

Email jacapdevila@vhebron.net
Abstract: For many years, the treatment of advanced pancreatic neuroendocrine tumors (pNETs) has been limited almost entirely to somatostatin analogs and streptozocin-based chemotherapy, with modest benefit. Increasing knowledge of the biologic features of pNETs has allowed the design of molecular-based clinical trials, which have taken a step forward in the management of these tumors. In this review, we discuss the molecular rationale for the development of everolimus for patients with advanced pNETs, critically review the clinical data obtained by the main studies in this setting, and discuss essential considerations based on recent findings in pNET biology for future drug development involving the phosphatidylinositol 3' kinaseAKT-mTOR pathway.

Keywords: pancreatic neuroendocrine tumors, everolimus, targeted therapies

\section{Introduction}

Neuroendocrine tumors are still "young" tumors, in that they were described much later than the vast majority of neoplasms. At the beginning of the 20th century, articles published by Professor Siegfried Oberndorfer informed the scientific community of these kinds of cancers, referred to as "carcinoids", which arise from neuroendocrine glands of the gastrointestinal tract and bronchial mucosa. In many regards, these cancers act like conventional carcinomas, although with more silent behavior. ${ }^{1}$

The estimated incidence of neuroendocrine tumors is $1-5$ cases per 100,000 population per year. During recent decades, a progressive increase has been reported in different national registries, although exact data are lacking, and the true incidence is suspected to be much higher. ${ }^{2,3}$ The annual incidence of pancreatic neuroendocrine tumors (pNETs) is calculated to be around 0.32 new cases per 100,000 population. However, as expected, in all well differentiated neuroendocrine tumors, the prevalence of these tumors is significantly higher, due primarily to their natural history, with neuroendocrine tumors now being the second most common advanced tumor of the gastrointestinal tract after colorectal cancer. ${ }^{3,4}$

Classically, pNETs have been divided/classified as either sporadic or hereditary, mainly in the setting of multiple endocrine neoplasm type 1, von Hippel-Lindau disease, neurofibromatosis type 1, or tuberous sclerosis syndrome (ranging between $5 \%$ and $30 \%$ of all pNETs), and as either functional or nonfunctional, depending on their capability to produce and release hormones and vasoactive peptides (up to $25 \%$ of pNETs). $)^{5,6}$

Although pNETs run an apparently indolent course, 5-year survival of patients with metastatic tumors is around $30 \% .{ }^{4}$ The mainstay of treatment for well and moderately 
differentiated pNETs is surgery to the primary tumor and associated metastases, mainly in the liver, with the main objective being removal of all existing tumor tissue, or at least an $80 \%-90 \%$ tumor reduction to have an impact on overall survival. Nevertheless, when resection of metastases is not feasible, surgery of the primary tumor should be taken into account, as well as local techniques directed to liver metastases, such as (chemo)embolization, hepatic radiofrequency, in very selected cases, liver transplantation. ${ }^{7-9}$

The classical approach for locally advanced or metastatic pNETs without the option for radical treatment has been limited almost entirely to somatostatin analogs, alfa interferon, and chemotherapy, with only modest results. ${ }^{7-9}$ Somatostatin analogs, such as octreotide and lanreotide, have demonstrated efficacy in the control of symptoms resulting from hormone release by pNETs in $70 \%-80 \%$ of cases. Side effects primarily affect the digestive tract and result from the inhibitory effects of somatostatin analogs; these occur in half of patients at a mild to moderate degree. ${ }^{8,9}$

The antiproliferative effect of somatostatin analogs have been widely discussed for many years. Preclinical and clinical evidence of this antitumoral activity has recently been established..$^{10}$ The results of the PROMID study in patients with advanced midgut neuroendocrine tumors demonstrated a significant benefit in time to progression in the octreotide arm compared with placebo. ${ }^{11}$ Data on pNETs are still lacking, but the results of the ongoing Phase III randomized clinical CLARINET trial comparing placebo versus lanreotide for the treatment of nonfunctioning enteropancreatic neuroendocrine tumors are expected in the near future. ${ }^{12}$ Alfa interferon has also been considered as a treatment option for controlling symptoms of hormone release, having an efficacy comparable with that of the somatostatin analogs, but with a worse toxicity profile, which has in turn limited the use of interferon alone or in combination with somatostatin analogs to refractory cases. ${ }^{8,9}$

Streptozocin-based chemotherapy has become the cornerstone of palliative treatment for pNETs, and was the only antiproliferative treatment approved by US Food and Drug Administration and the European Medicines Agency prior to the arrival of targeted therapies. Several studies have been developed, but there is no homogeneity between them regarding chemotherapy regimens, neuroendocrine tumor origin or functionality, nor their methods of response assessment. Given this discrepancy, it has been extremely complicated to extract solid conclusions regarding the usefulness of chemotherapy in this setting, considering an overall response rate typically in the range of $20 \%-60 \% .^{7-9}$ However, more recent analyses of antitumoral activity reveal reduced efficacy of chemotherapy in advanced pNETs for $16 \%$ of patients in first-line therapy and only $4 \%$ in second-line therapy. ${ }^{6}$

In recent years, the molecular biology of pNETs has become better understood, and three main pathways have been found to be involved in development of pNETs, ie, the phosphatidylinositol 3' kinase (PI3K)-AKT-mTOR pathway, growth signaling pathways such as those mediated by the epidermal growth factor receptor and the insulin-like growth factor receptor, and the receptors and ligands related to angiogenesis. Given the better characterization of the phenotypic features of pNETs, therapies against some of these targets have been developed, with promising results. ${ }^{13,14}$ The aim of this review is to provide a critical approach to the molecular rationale for targeting the mTOR pathway in pNETs and the role of everolimus in this setting.

\section{Preclinical rationale}

The mammalian target of rapamycin (mTOR) is a serine/ threonine kinase encoded by the FRAP 1 gene discovered in the yeast Saccharomyces cerevisiae.$^{15} \mathrm{mTOR}$ is involved in many physiologic processes, including cell growth, ribosome biogenesis, control of the actin cytoskeleton, autophagy, synthesis of amino acids and glucose, adipogenesis, and translation of mRNAs encoding essential proteins for cell survival during stressful situations (such as hypoxia or lack of nutrients). ${ }^{15}$

In general terms, mTOR is a downstream molecule in the PI3K-AKT signaling pathway. This pathway is regulated by molecules such as insulin, epidermal, and platelet-derived or vascular endothelial growth factors, which are capable of activating the pathway by joining of their transmembrane receptors.

Two main protein complexes have been described for mTOR and the mTOR complex 1 and 2, with different regulators and functions. ${ }^{15}$ mTORC1, rapamycin-sensitive, is the best known complex and is activated upstream by the PI3K-AKT pathway and controlled by PTEN and the TSC1/TSC2 complex. mTORC1 has two main effectors, ie, S6K1 (ribosomal protein S6 kinase) and 4EBP1 (translational repressor protein eukaryotic initiation factor 4E binding protein 1), which are important key regulators of ribosomal functioning and protein synthesis, such as proteins involved in the synthesis of glycogen and hypoxiainducible factor $\alpha 1$ (see Figure 1). ${ }^{15}$

However, mTORC2, rapamycin-resistant, is activated directly by protein kinase C- $\alpha$, and is also involved in AKT regulation. The main effectors are small GTPases related to 


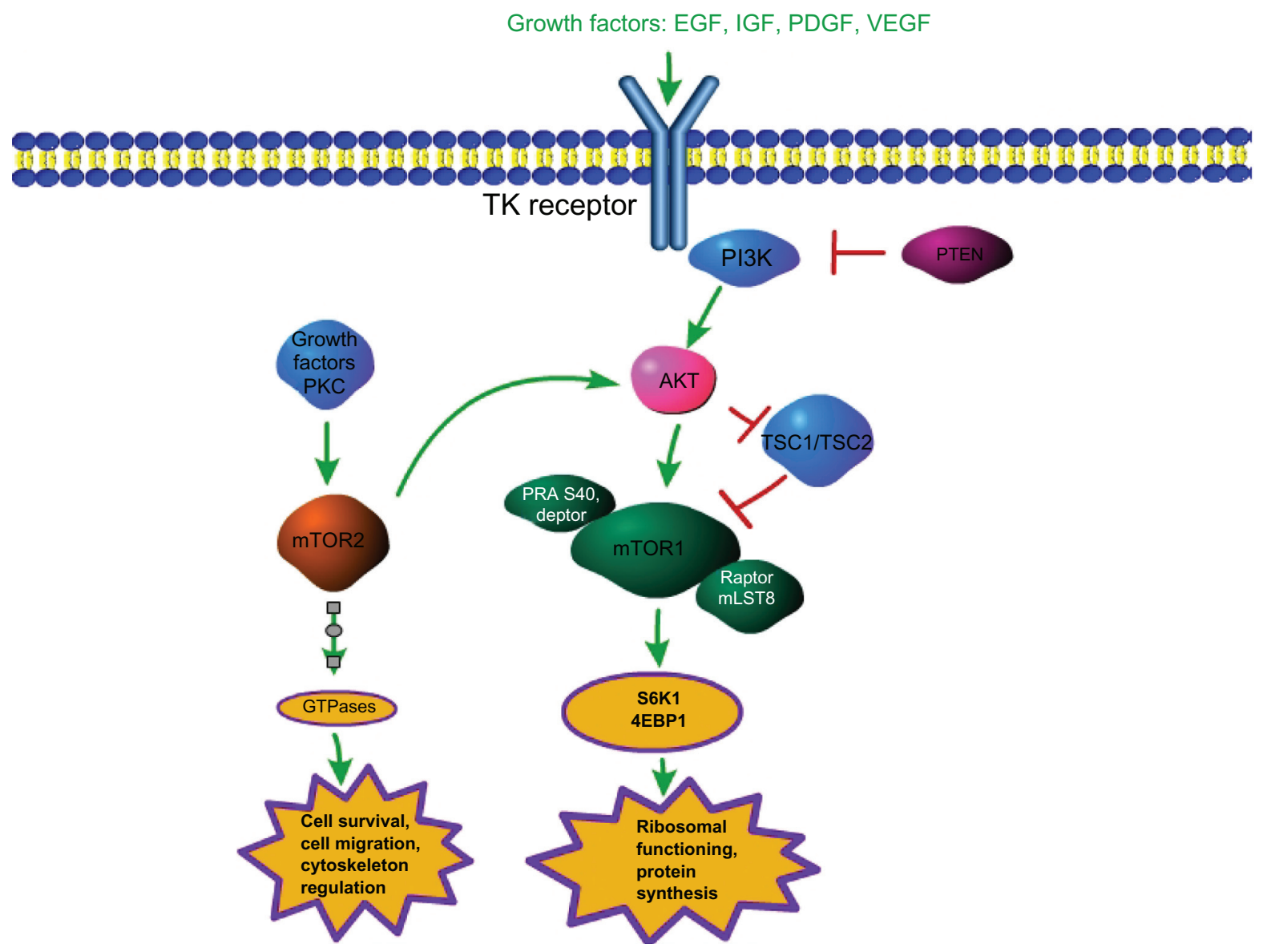

Figure I PI3K-AKT-mTOR pathway.

Abbreviations: EGF, epidermal growth factor; IGF, insulin growth factor; PI3K, phosphatidylinositol 3' kinase; PDGF, platelet-derived growth factor; VEGF, vascular endothelial growth factor; TK, tyrosine kinase; S6KI, ribosomal protein S6 kinase; 4EBPI translational repressor protein eukaryotic initiation factor 4E binding protein I; raptor and MLST8, intrinsic positive regulators of mTORI complex; PRAS40 and DEPTOR, intrinsic negative regulators of mTORI complex.

cell survival and migration processes and to regulation of the actin cytoskeleton. ${ }^{15}$

Disturbances in mTOR regulators (in the upstream pathway or regulatory molecules) and/or in mTOR itself have been described in up to half of human cancers. For this reason, the mTOR signaling pathway has become one of the most targeted cancer pathways during the last decade. ${ }^{16-19}$

There are preclinical models of pNET cell lines that show high phosphorylated mTOR expression levels, indicating the relevance of this molecule in the pathogenesis of pNETs.$^{20}$ Moreover, treatment of pNET cell lines with RAD001 (everolimus), a mTORC1 inhibitor, inhibits growth by decreasing the S-phase and increasing the G0/G1 phase of the cell cycle in a dose-dependent manner, providing a rationale for the treatment of pNETs with everolimus. ${ }^{10,19,20}$ BON cell lines and their response to treatment with everolimus are good examples and proof of this concept. ${ }^{21}$

mTOR is highly involved in the pathogenesis of pNETs, but its mechanisms of action are not completely understood.
Gene expression analyses of pNETs have found mutations in the mTOR pathway in up to $14 \%$ of cases. Moreover, genetic aberrations or alterations in the functional capacity of suppressor proteins in the mTOR pathway (such as PTEN or TSC2) have been found in up to $80 \%$ of advanced pNETs. ${ }^{22,23}$ Further, hereditary syndromes with constitutive activation of the mTOR pathway, such as von Hippel-Lindau, neurofibromatosis type 1 , or tuberous sclerosis, have a higher incidence of pNETs. ${ }^{14}$

\section{Phase II-III studies of everolimus in PNETs}

Everolimus was approved by the FDA for the treatment of advanced pNETs in 2011, as a result of evidence provided by the RADIANT-III trial, and took a step forward in pNET management. ${ }^{24}$ Some of the first clinical evidence of the inhibitory activity of mTOR in neuroendocrine tumors was reported by Duran et al in 2006 from a Phase II trial studying the activity of temsirolimus in these tumors (including 
a study subpopulation with pNETs). ${ }^{25}$ It was not until two years later that the specific activity of everolimus in pNETs was published by Yao et al. ${ }^{26}$ In their Phase II study, 30 patients with carcinoid tumors and 30 patients with pNETs were included in two consecutive cohorts. The first cohort treated 30 patients with a combination of depot octreotide $30 \mathrm{mg}$ intramuscularly every 28 days plus everolimus $5 \mathrm{mg}$ daily. The second cohort included 30 patients treated with octreotide at the same doses and everolimus $10 \mathrm{mg}$ daily. The authors reported promising antitumor activity, with a response rate of $27 \%$ in pNETs and a median progression-free survival of 50 weeks. The survival rates at years 1, 2, and 3 were $83 \%, 81 \%$, and $78 \%$, respectively. Moreover, patients included in the cohort of everolimus $10 \mathrm{mg}$ had a higher response rate (30\% versus $13 \%)$ and a prolonged median progression-free survival ( 72 versus 50 weeks). These results are consistent with the recommended dose and schedule of everolimus in the Phase I pharmacodynamic study. ${ }^{18} \mathrm{~A}$ further $70 \%$ of patients with elevated chromogranin A levels achieved normalization or more than $50 \%$ reduction. Overall, treatment was well tolerated, and the most frequent grade 3-4 adverse events were aphthous ulcers, fatigue, diarrhea, hyperglycemia, and hypophosphatemia. ${ }^{26}$

The promising results of this pivotal study led to the design of the RADIANT trials. The RADIANT-I study was an open-label, nonrandomized, multicenter Phase II trial of everolimus in advanced pNETs with progressive disease during or after chemotherapy that was stratified by ongoing octreotide therapy at study entry. ${ }^{27}$ The primary endpoint was objective response rate in stratum 1 (everolimus $10 \mathrm{mg}$ daily), and secondary endpoints were objective response rate in stratum 2 (everolimus $10 \mathrm{mg}$ daily plus octreotide LAR), progression-free survival, duration of response, overall survival, safety, and pharmacokinetics. One hundred and sixty patients were enrolled, with 115 in stratum 1 and 45 in stratum 2, the characteristics of whom are described in Table 1.

As shown in Table 2, the benefit of everolimus in patients with pNETs refractory to chemotherapy was mainly disease stabilization, rather than partial or complete tumor responses measured by RECIST (Response Evaluation Criteria In Solid Tumors) criteria. Although this study was not designed to evaluate the combination of everolimus and octreotide, it appears that this combination achieved better rates of disease stabilization and longer progression-free survival, and there were no cases of disease progression as the best initial response.

The toxicity profile of everolimus was similar to that observed in other clinical trials involving solid tumors, even
Table I Baseline characteristics of RADIANT I study population ${ }^{27}$

\begin{tabular}{|c|c|c|}
\hline & $\frac{\text { Arm I }(n=I \mid 5)}{\text { Everolimus }}$ & $\begin{array}{l}\text { Arm } 2(n=45) \\
\text { Everolimus + octreotide } \\
\text { LAR }\end{array}$ \\
\hline Median age & 55 & 55 \\
\hline $\begin{array}{l}\text { World Health } \\
\text { Organization PS } 0\end{array}$ & $58.3 \%$ & $71.1 \%$ \\
\hline $\begin{array}{l}\text { Histologic grade } \\
\text { well-differentiated }\end{array}$ & $76.5 \%$ & $77.8 \%$ \\
\hline $\begin{array}{l}\text { Time since initial } \\
\text { diagnosis }>5 \text { years }\end{array}$ & $34.8 \%$ & $40 \%$ \\
\hline Stage IV & $100 \%$ & $98 \%$ \\
\hline Liver metastases & $94.8 \%$ & $93.3 \%$ \\
\hline $\begin{array}{l}\text { One prior } \\
\text { chemotherapy regimen }\end{array}$ & $53.9 \%$ & $48.9 \%$ \\
\hline
\end{tabular}

in combination with octreotide. The most common adverse events observed were mild in severity, and included stomatitis, rash, diarrhea, fatigue, and nausea. Grade 3-4 adverse events are shown in Table 3.

Two of the most frightening events related to mTOR inhibition, ie, opportunistic infections and interstitial pneumonitis, were only observed at the reversible grade $1-2$ level, but none of grade 3-4 severity. The results of the multicenter Phase II RADIANT-I trial confirmed the activity of everolimus in the treatment of advanced pNETs with acceptable toxicity. However, this evidence was weaker compared with that in the pivotal study regarding response rate measured by RECIST criteria, but the disease control rate was comparable in both studies. ${ }^{26,27}$

Final confirmation of the activity of everolimus in advanced pNETs was reported by the double-blind, placebocontrolled, Phase III RADIANT-III trial. ${ }^{24}$ This study included

Table 2 Summary of results (data shown belong to central radiology review, but study also includes data reviewed by investigators $)^{27}$

\begin{tabular}{|c|c|c|}
\hline & Arm I $(n=I \mid 5)$ & Arm $2(n=45)$ \\
\hline & Everolimus & $\begin{array}{l}\text { Everolimus + } \\
\text { octreotide LAR }\end{array}$ \\
\hline Response & PE $9.6 \%$ & $4.4 \%$ \\
\hline rate & $(95 \% \mathrm{Cl} 4.9-16.5)$ & $(95 \% \mathrm{Cl} 0.5-15)$ \\
\hline Duration & 10.6 months & Not calculated \\
\hline response & (95\% Cl 9.8-NR) & \\
\hline $\begin{array}{l}\text { Stabilization } \\
\text { disease }\end{array}$ & $67.8 \%$ & $80 \%$ \\
\hline $\begin{array}{l}\text { Progression } \\
\text { disease }\end{array}$ & $13.9 \%$ & 0 \\
\hline PFS & $\begin{array}{l}9.7 \text { months } \\
(95 \% \mathrm{Cl} 8.3-13.3)\end{array}$ & $\begin{array}{l}16.7 \text { months } \\
(95 \% \mathrm{Cl} \text { II.I-NR) }\end{array}$ \\
\hline OS & $\begin{array}{l}24.9 \text { months } \\
\text { ( } 95 \% \mathrm{Cl} 20.2-27 . I \text { months })\end{array}$ & NR \\
\hline
\end{tabular}

Abbreviations: $\mathrm{Cl}$, confidence interval; NR, not reached; PFS, progression-free survival; OS, overall survival; $\mathrm{PE}$, primary endpoint. 
Table 3 Adverse events grade 3-4 related to everolimus in both $\operatorname{arms}^{27}$

\begin{tabular}{ll}
\hline Adverse event grade 3-4 & Both arms \\
\hline Stomatitis & $6.6 \%$ \\
Diarrhea & $3.5 \%$ \\
Fatigue & $6.5 \%$ \\
Asthenia & $7.4 \%$ \\
Anemia & $8.7 \%$ \\
Anorexia & $5.3 \%$ \\
Hyperglycemia & $8.7 \%$ \\
Thrombocytopenia & $11.5 \%$ \\
Neutropenia & $4.3 \%$ \\
\hline
\end{tabular}

patients with locally advanced or metastatic pNETs of low or intermediate histologic grade randomized to receive everolimus $10 \mathrm{mg}$ daily or placebo, both arms in combination with best supportive care allowing somatostatin analogs. ${ }^{24}$ Treatment was continued until disease progression or appearance of unacceptable toxicity. Participants were stratified according to World Health Organization (WHO) performance status at baseline ( 0 versus 1 or 2 ) and prior chemotherapy. Crossover was allowed after failure on placebo. The primary endpoint was progression-free survival, and secondary endpoints included objective response rate, duration of response, overall survival, and safety. Four hundred and ten patients were enrolled, 207 of whom were assigned to the everolimus arm and 203 to the placebo arm, with clinical characteristics being well balanced between both arms (Table 4).

Progression-free survival (the primary endpoint of the study) in the everolimus arm as assessed by local investigators was 11 months, compared with 4.6 months in the placebo arm, with a $65 \%$ reduction in risk of tumor progression (hazards ratio $0.35,95 \%$ confidence interval [CI] 0.27-0.45, $P<0.001)$. This benefit was observed in all subgroups of patients, ie, those who had had prior chemotherapy or were chemonaïve, WHO performance status (0 versus 1 or 2 ), age, gender, race, geographic region, prior treatment with

Table 4 Baseline characteristics of the RADIANT-III study population $^{24}$

\begin{tabular}{lll}
\hline & $\begin{array}{c}\text { Everolimus } \\
\mathbf{n = 2 0 7}\end{array}$ & $\begin{array}{l}\text { Placebo } \\
\mathbf{n = 2 0 3}\end{array}$ \\
\hline Median age & 58 & 57 \\
World Health Organization PS 0 & $67 \%$ & $66 \%$ \\
Previous chemotherapy & $50 \%$ & $50 \%$ \\
Previous somatostatin analog & $49 \%$ & $50 \%$ \\
Well differentiated pancreatic & $82 \%$ & $84 \%$ \\
neuroendocrine tumors & & \\
Years from initial diagnosis $>2$ & $57 \%$ & $63 \%$ \\
Liver metastases & $92 \%$ & $92 \%$ \\
\hline
\end{tabular}

somatostatin analogs, and tumor grade (well differentiated versus moderately differentiated).

Similar to the Phase II study results, the improvement in progression-free survival was mainly due to disease stabilization rather than partial tumor responses measured by RECIST criteria. However, patients who achieved a minor response (tumor reduction 1\%-29\%) were up to 59\% in the everolimus arm (compared with $18 \%$ in the placebo arm). This group also showed higher benefit in tumor growth control than reflected by RECIST criteria, raising the controversial drug activity evaluation of new targeted therapies in solid tumors using classical criteria (RECIST/WHO, Table 5).

As expected, no differences were observed in overall survival due to a trial design that allowed immediate crossover to the everolimus arm for those patients treated with placebo after tumor progression. This crossover occurred in $73 \%$ of patients in the placebo arm, so final analysis of overall survival is still pending. The majority of adverse events related to everolimus were mild to moderate, and similar to those described in the Phase II trials. Main grade 3 or 4 adverse events are shown in Table 6.

In summary, the results of the RADIANT-III trial concluded that everolimus had the clinical benefit of 6.4 months of progression-free survival in locally advanced or metastatic pNETs compared with placebo, with an acceptable safety profile. ${ }^{24}$ It is still unknown whether in this context combination with somatostatin analogs is effective, especially considering the results of the Phase II trial. However, an exploratory analysis of the RADIANT-III study showed significant improvement in progression-free survival in the everolimus arm regardless of the pattern of somatostatin analog use, including both those who had never before received this therapy and those who received it during the study (Table 7). ${ }^{28}$

\section{Next steps in development of everolimus for pNETs}

In the RADIANT-I study, the combination of everolimus with somatostatin analogs seemed to provide better clinical

Table 5 Best responses achieved in each arm of treatment in the RADIANT-III study ${ }^{24}$

\begin{tabular}{lll}
\hline & $\begin{array}{l}\text { Everolimus } \\
(\mathbf{n}=\mathbf{2 0 7})\end{array}$ & $\begin{array}{l}\text { Placebo } \\
(\mathbf{n}=\mathbf{2 0 3})\end{array}$ \\
\hline Partial response & $5 \%$ & $2 \%$ \\
Stabilization disease & $73 \%$ & $51 \%$ \\
Progression disease & $14 \%$ & $42 \%$ \\
Minor response & $59 \%$ & $18 \%$ \\
\hline
\end{tabular}


Table 6 Adverse events grade 3-4 related to everolimus ${ }^{24}$

\begin{tabular}{ll}
\hline Adverse event grade 3-4 & Everolimus arm \\
\hline Stomatitis & $7 \%$ \\
Diarrhea & $3 \%$ \\
Fatigue & $2 \%$ \\
Asthenia & $1 \%$ \\
Anemia & $6 \%$ \\
Infections & $2 \%$ \\
Hyperglycemia & $5 \%$ \\
Thrombocytopenia & $4 \%$ \\
Neutropenia & $4.3 \%$ \\
Nausea & $2 \%$ \\
Pneumonitis & $2 \%$ \\
\hline
\end{tabular}

benefit than everolimus alone. However, the study was not designed to compare these options directly, and neither can RADIANT-III speak to this at the present time. ${ }^{24,27}$ There exists preclinical and clinical evidence of an antiproliferative effect of somatostatin analogs in neuroendocrine tumors and, although the exact mechanism is not yet clear, it appears to be related to mTOR inhibition as well. ${ }^{10,11}$ It has been demonstrated in preclinical models that the combination of mTOR inhibitors and somatostatin analogs has antiproliferative effects due to the action of both drugs, ${ }^{10}$ but data in the clinical setting are still lacking, pending the results of ongoing clinical trials (Table 8$).{ }^{12}$

As mentioned earlier, the rationale for treatment of pNETs with everolimus is related to the high activation of the PI3K-AKT-mTOR pathway in these neoplasms. ${ }^{19,20,22}$ Preclinical models and clinical trials are currently investigating blockade of mTOR in combination with other targeted therapies against upstream molecules in the mTOR pathway, including the epidermal growth factor receptor and insulinlike growth factor receptor.

In physiologic or pathologic situations in which mTOR is overactivated, downstream effectors of mTOR, mainly pS6 kinase, are capable of producing a negative feedback loop in order to control pathway signaling. Although the

Table 7 Exploratory analysis of RADIANT-III: comparison of the impact of somatostatin analog treatment in progression-free survival in both arms

\begin{tabular}{ll}
\hline Variable & PFS \\
\hline Any somatostatin & II .4 months $(E)$ versus 3.9 months $(P)$ \\
analog treatment & HR $0.40(95 \% \mathrm{Cl} 0.29-0.56)$ \\
No somatostatin & I0.8 months $(E)$ versus 4.6 months $(P)$ \\
analog treatment & HR $0.35(95 \%$ Cl $0.24-0.50)$ \\
\hline
\end{tabular}

Abbreviations: $\mathrm{Cl}$, confidence interval; $\mathrm{E}$, everolimus arm; $\mathrm{HR}$, hazards ratio; $\mathrm{P}$, placebo arm; PFS, progression-free survival. ${ }^{28}$ mechanism is not well understood, preclinical evidence shows that mTOR exercises the negative feedback loop by attenuating signals from the insulin growth factor receptor. ${ }^{29}$ However, when mTOR is inhibited, for example by rapamycin, this negative feedback loop is lost, leading to enhanced signaling in the PI3K-AKT-mTOR pathway from the insulin-like growth factor receptor and other growth factor receptors which, in turn, lead to upregulation of phosphorylated AKT levels, crosstalk with other signaling pathways, and consequent reduction of the mTOR inhibition effect..$^{29,30}$ These mechanisms provide a rationale for the combination of mTOR inhibitors with other targeted therapies against upstream effectors of the mTOR pathway. In preclinical models, resistance to mTOR inhibition with rapamycin could be avoided by addition of erlotinib, an epithelial growth factor receptor inhibitor. ${ }^{18}$

Double inhibition strategies involving mTOR and vascular endothelial growth factor receptor with bevacizumab or mTOR with tyrosine kinase inhibitors are also currently in clinical development for advanced neuroendocrine tumors, with initially promising results (Table 9). ${ }^{31}$

\section{Unmet needs}

For many years, streptozocin-based chemotherapy has been the only approved regimen for the systemic antitumoral treatment of advanced pNETs, with discrepant results between studies, limited clinical benefit, and significant toxicity. ${ }^{7}$ Fortunately, with a deeper knowledge of the tumorigenic pathways involved in the pathogenesis of pNETs, some targets and targeted therapies have been identified and developed, with encouraging results.

The results of the RADIANT-III study clearly demonstrate a significant benefit of everolimus in progression-free survival for patients with advanced pNETs. ${ }^{24}$ However, not all patients responded to therapy to the same degree. There is a real unmet need for surrogate predictive biomarkers of response, not only for everolimus, but for all targeted therapies in the management of neuroendocrine tumors. Currently, few biomarkers have been proposed to be correlated with the efficacy of everolimus, but include a rapid decrease in chromogranin A levels after the beginning of everolimus treatment and in baseline levels of phospho-AKT. ${ }^{26}$

Although a preclinical rationale for combination of everolimus with somatostatin analogs exists, no prospective clinical evidence is available. Retrospective analyses have suggested a synergistic or at least additive effect of the combination of somatostatin analogs with 
Table 8 Ongoing clinical trials with everolimus plus somatostatin analogs ${ }^{12}$

\begin{tabular}{|c|c|c|c|}
\hline Title & Status & Phase & Intervention \\
\hline $\begin{array}{l}\text { Efficacy of everolimus alone or in combination } \\
\text { with pasireotide LAR in advanced PNET } \\
\text { (COOPERATE-I) } \\
\text { (NCTOI37445I) }\end{array}$ & Recruiting & II & $\begin{array}{l}\text { Everolimus versus } \\
\text { everolimus + pasireotide LAR }\end{array}$ \\
\hline $\begin{array}{l}\text { Everolimus plus octreotide depot in metastatic or } \\
\text { unresectable low grade neuroendocrine carcinoma } \\
\text { (NCTO0I I3360) }\end{array}$ & Completed & II & Everolimus + octreotide LAR \\
\hline $\begin{array}{l}\text { Everolimus combined with octreotide LAR to } \\
\text { treat advanced GI NET } \\
\text { (EVERLAR) } \\
\text { (NCT0I567488) }\end{array}$ & Recruiting & II & Everolimus + octreotide LAR \\
\hline
\end{tabular}

Abbreviation: GI NET, gastrointestinal neuroendocrine tumor.

targeted therapies. ${ }^{28,32}$ In current clinical practice, the combination of such treatments is quite common, but the real impact of this approach needs to be confirmed in prospective clinical trials.

In addition to everolimus, sunitinib, a multiple tyrosine kinase receptor inhibitor with antiangiogenic effects, has also demonstrated an increase in progression-free survival of 6 months (hazards ratio $0.42, P<0.001$ ) in the same setting. ${ }^{33}$ As a result, the medical community currently has two options for the treatment of locally advanced or metastatic pNETs with targeted therapies, ie, sunitinib and everolimus. However, no data are currently available about which of these should be used in first-line or second-line therapy. Moreover, the arrival of targeted therapies for management of advanced pNETs needs to face the reality of chemotherapy, the standard treatment for these patients for many years. Although the results are not without controversy, chemotherapy is clearly active in some patients. Prospective clinical trials comparing both approaches are currently ongoing and will assess the best treatment sequence for these patients. ${ }^{12}$

The natural history of pNETs will allow patients to receive most available treatments during evolution of the disease. The concept of sequential therapies is quickly growing in this field, and future clinical trials will assess the role and position of everolimus, alone or in combination with other targeted therapies, somatostatin analogs, and chemotherapy to overcome the resistance to $\mathrm{mTOR}$ inhibition and prolong patient survival.

Last but not least, the development of an ambitious predictive biomarker program is urgently needed to improve patient selection. In the RADIANT-III study, 34\% of patients achieved prolonged clinical benefit from over 18 months with everolimus, indicating a subgroup of patients with increased drug efficacy who should be clearly identified and treated.

Table 9 Ongoing clinical studies of mTOR inhibitors with other targeted therapies in neuroendocrine tumors ${ }^{12}$

\begin{tabular}{|c|c|c|c|}
\hline Title & Status & Phase & Intervention \\
\hline $\begin{array}{l}\text { Everolimus and octreotide with or without bevacizumab in } \\
\text { treating patients with locally advanced or metastatic pancreatic } \\
\text { neuroendocrine tumors that cannot be removed by surgery } \\
\text { (NCTOI229943) }\end{array}$ & Recruiting & II & $\begin{array}{l}\text { Everolimus + octreotide versus } \\
\text { everolimus }+ \text { octreotide }+ \text { bevacizumab }\end{array}$ \\
\hline $\begin{array}{l}\text { Sorafenib in combination with everolimus in patients } \\
\text { with advanced neuroendocrine tumors } \\
\text { (NCT00942682) }\end{array}$ & $\begin{array}{l}\text { Active, not } \\
\text { recruiting }\end{array}$ & I & Sorafenib + everolimus \\
\hline $\begin{array}{l}\text { Everolimus and erlotinib in patients with neuroendocrine tumors } \\
\text { (NCT0084353I) }\end{array}$ & Recruiting & II & Everolimus + erlotinib \\
\hline $\begin{array}{l}\text { Bevacizumab and everolimus in advanced low or intermediate } \\
\text { grade neuroendocrine carcinoma } \\
\text { (NCT00607II3) }\end{array}$ & Completed & II & Bevacizumab + everolimus \\
\hline $\begin{array}{l}\text { Temsirolimus and bevacizumab in treating patients with locally } \\
\text { advanced, recurrent, metastatic, or progressive endometrial } \\
\text { cancer, ovarian epithelial cancer, liver cancer, islet cell cancer, } \\
\text { or carcinoid tumor } \\
\text { (NCT0I0I0I26) }\end{array}$ & Recruiting & II & Bevacizumab + temsirolimus \\
\hline
\end{tabular}




\section{Conclusion}

Identification of the role of the mTOR pathway in the pathogenesis of neuroendocrine tumors has allowed the development of specific mTOR inhibitors in this setting. Unfortunately, demonstration of significant efficacy has only been confirmed in pNETs. However, relevant activity has been shown in a wider group of NETs, but the lack of predictive biomarkers has conditioned the initial failure of clinical trials. Everolimus will become a cornerstone in the treatment of advanced pNETs, and should be integrated into the treatment options available for these patients.

\section{Acknowledgments}

The authors acknowledge Eric Johnson for writing advice.

\section{Disclosure}

The authors report no conflicts of interest in this work.

\section{References}

1. Modlin I, Shapiro MD, Kidd M, Eick G. Siegfried Oberndorfer and the evolution of carcinoid disease. Arch Surg. 2007;142:187-197.

2. Hemminli $\mathrm{K}, \mathrm{Li} \mathrm{X}$. Incidence trends and risk factors of carcinoid tumors: a nationwide epidemiologic study from Sweden. Cancer. 2001;92:2204-2210.

3. Yao C, Hassan M, Phan A, et al. One hundred years after "carcinoid": epidemiology of and prognostic factors for neuroendocrine tumors in 35.825 cases in the United States. J Clin Oncol. 2008;26: 3063-3072.

4. Modlin IM, Lye KD, Kidd M. A 5-decade analysis of 13,715 carcinoid tumors. Cancer. 2003;97:934-959.

5. Levi F, Te V-C, Randimbison L, Rindi G, La Vecchia C. Epidemiology of carcinoid neoplasms in Vaud, Switzerland, 1974-1997. Br J Cancer. 2000;83:952-955.

6. García-Carbonero R, Capdevila J, Crespo-Herrero G, et al. Incidence, patterns of care and prognostic factors for outcome of gastroenteropancreatic neuroendocrine tumors (GEP-NETs): results from the National Cancer Registry of Spain (RGETNE). Ann Oncol. 2010;21:1794-1803.

7. Kouvaraki M, Ajani J, Hoff P, et al. Fluorouracil, doxorubicin, and streptozocin in the treatment of patients with locally advanced and metastatic pancreatic endocrine carcinomas. J Clin Oncol. 2004;22: 4762-4771.

8. ENETS 2011. Consensus guidelines for the management of patients with digestive neuroendocrine tumors. Neuroendocrinology. 2012;95: $67-178$.

9. Kulke MH, Anthony LB, Bushnell DL, et al. NANETS treatment guidelines: well-differentiated neuroendocrine tumors of the stomach and pancreas. Pancreas. 2010;39:735-752.

10. Grozinsky-Glasberg, Franchi G, Teng M, et al. Octeotride and the mTOR inhibitor RAD001 (everolimus) block proliferation and interact with the Akt-mTOR-p70S6K pathway in a neuro-endocrine tumor cell line. Neuroendocrinology. 2008;87:168-181.

11. Rinke A, Müller H, Schade-Brittinger, et al. Placebo-controlled, doubleblind, prospective, randomized study on the effect of octreotide LAR in the control of tumor growth in patients with metastatic neuroendocrine midgut tumors: a report from the PROMID Study Group. J Clin Oncol. 2009;27:4656-4663.

12. Clinical Trials. gov. US National Institutes of Health. Available from: http://www.clinicaltrials.gov. Accessed on May 30, 2012.
13. Capdevila J, Tabernero J. A shining light in the darkness for the treatment of pancreatic neuroendocrine tumors. Cancer Discov. 2011;1:213-221.

14. Capdevila J, Salazar R, Halperín I, Abad A, Yao JC. Innovations therapy: mammalian target of rapamycin (mTOR) inhibitors for the treatment of neuroendocrine tumors. Cancer Metastasis Rev. 2011;30:27-34.

15. Pópulo H, Lopes JM, Soares P. The mTOR signalling pathway in human cancer. Int J Mol Sci. 2012;13:1886-1918.

16. Albanell J, Dalmases A, Rovira A, et al. mTOR signalling in human cancer. Clin Transl Oncol. 2007;9:484-493.

17. O'Donnell A, Faivre S, Burris HA III, et al. Phase I pharmacokinetic and pharmacodynamic study of the oral mammalian target of rapamycin inhibitor everolimus in patients with advanced solid tumors. $J$ Clin Oncol. 2008;26:1588-1595.

18. Tabernero J, Rojo F, Calvo E, et al. Dose- and schedule-dependent inhibition of the mammalian target of rapamycin pathway with everolimus: a Phase I tumor pharmacodynamic study in patients with advanced solid tumors. J Clin Oncol. 2008;26:1603-1610.

19. Chiu C, Nozawa H, Hanahan D. Survival benefit with proapoptotic molecular and pathologic responses from dual targeting of mammalian target of rapamycin and epidermal growth factor receptor in a preclinical model of pancreatic neuroendocrine carcinogenesis. J Clin Oncol. 2010;28:4425-4433.

20. Hörsch D, Tielke S, Schrader J. Expression and activation of mTOR in neuroendocrine tumors: Effect of mTor inhibition by RAD001 upon growth, cell cycle regulation and signaling in neuroendocrine cell lines. J Clin Oncol. 2007;25 Suppl:Abstr 10570.

21. Zitzmann K, De Toni EN, Brand S, et al. The novel mTOR inhibitor RAD001 (everolimus) induces antiproliferative effects in human pancreatic neuroendocrine tumor cells. Neuroendocrinology. 2007;85:54-60.

22. Jiao Y, Shi C, Edil BH, et al. DAXX/ATRX, MEN 1 and mTOR pathway genes are frequently altered in pancreatic neuroendocrine tumors. Science. 2011;331:1199-1203.

23. Missiaglia E, Dalai I, Barbi S, et al. Pancreatic endocrine tumors: expression profiling evidences a role for AKT mTOR pathway. J Clin Oncol. 2010;28:245-255.

24. Yao J, Shah M, Ito T, et al. Everolimus for advanced pancreatic neuroendocrine tumors. N Engl J Med. 2011;364:514-523.

25. Duran I, Kortmansky J, Singh D, et al. A Phase II clinical and pharmacodynamic study of temsirolimus in advanced neuroendocrine carcinomas. Br J Cancer. 2006;95:1148-1154.

26. Yao J, Phan A, Chang D, et al. Efficacy of RAD001 (everolimus) and octreotide LAR in advanced low- to intermediate-grade neuroendocrine tumors: results of a Phase II study. J Clin Oncol. 2008;26:4311-4318.

27. Yao J, Lombard-Bohas C, Baudin E, et al. Daily oral everolimus activity in patients with metastatic pancreatic neuroendocrine tumors after failure of cytotoxic chemotherapy: a Phase II trial. J Clin Oncol. 2010;28:69-76.

28. Shah MH, Lombard-Bohas C, Ito T, et al. Everolimus in patients with advanced pancreatic neuroendocrine tumors (pNET): impact of somatostatin analog use on progression-free survival in the RADIANT-3 trial. J Clin Oncol. 2011;29 Suppl:4013.

29. O'Reilly, Rojo F, She QB, et al. mTOR inhibition induces upstream receptor tyrosine kinase signaling and activates Akt. Cancer Res. 2006;66:1500-1508.

30. Wan X, Harkavy B, Shen N, Grohar P, Helman LJ. Rapamycin induces feedback activation of Akt signaling through an IGF-1R-dependent mechanism. Oncogene. 2007;26:1932-1940.

31. Hobday T, Qin R, Reidy DL, et al. Multicenter phase II trial of temsirolimus (TEM) and bevacizumab (BEV) in pancreatic neuroendocrine tumor (PNET). J Clin Oncol. 2012;30 Suppl 4:Abstr 260.

32. Capdevila J, Sevilla I, Alonso V, et al. Evaluation of safety and efficacy of somatuline autogel in combination with molecular targeted therapies (MTT) in patients with neuroendocrine tumors (NETs): data from one Spanish cohort. J Clin Oncol. 2012;30 Suppl:Abstr 14671.

33. Raymond E, Dahan L, Raoul JL, et al. Sunitinib malate for the treatment of pancreatic neuroendocrine tumors. $N$ Engl J Med. 2011;364:501-513. 
Gastrointestinal Cancer: Targets and Therapy

Dovepress

\section{Publish your work in this journal}

Gastrointestinal Cancer: Targets and Therapy is an international, peer-reviewed, open access journal focusing on gastro-intestinal cancer research, identification of therapeutic targets and the optimal use of preventative and integrated treatment interventions to achieve improved outcomes, enhanced survival and quality of life for the cancer patient. The manuscript management system is completely online and includes a very quick and fair peer-review system. Visit $\mathrm{http} / / / \mathrm{ww} w$. dovepress.com/testimonials.php to read real quotes from published authors.

Submit your manuscript here: http://www.dovepress.com/gastro-intestinal-cancer-targets-and-therapy-journal 